\title{
Improving the scientific literacy of Aboriginal students through astronomy
}

\author{
Ragbir Bhathal \\ UWS Observatory, \\ University of Western Sydney, Locked Bag 1797, \\ Penrith South DC NSW 1797, Australia \\ email: r.bhathal@uws.edu.au
}

\begin{abstract}
Seventy per cent of Aboriginal students drop out of school before the end of their secondary school years and very few go on to do science at the Higher School Certificate level. As a result of this statistics reveal that only $0.003 \%$ of the 9000 university science graduates in 2005 in Australia were of Aboriginal origin. This paper discusses an astronomy project which seeks to improve the scientific literacy of Aboriginal students so as to motivate them to take up careers in science and engineering.
\end{abstract}

Keywords. Scientific literacy, Aboriginal students, Aboriginal astronomy

\section{Introduction}

Long before the Europeans landed on the shores of Australia, Malay fishermen from the South-east Asian countries had been carrying on trading activities with the Aboriginal people of northern Australia. A few European vessels had landed on Australian soil in the early years of the 18th century but for the most part it remained an unknown land. Even its coastline had not been charted. But this was to change in the second half of the 18 th century with dire consequences for its original inhabitants.

After making the observations of the transit of Venus at Tahiti in June 1769 Cook had instructions to sail westwards to search for a "southern continent". On 19th April 1770 he sighted Cape Everard near the south-east extremity of the Australian mainland. As their ship made its way north along the coast of New South Wales, the Aboriginal inhabitants lit fires to warn their people of strangers along their shores; on board the Endeavour the young naturalist, Joseph Banks, on first sighting Australia, wrote in his diary, "large fires were lighted this morn at 10 o'clock" (Badger 1970).

For the next several months Cook explored and mapped the eastern coast of Australia. He carried out nautical astronomy along the coast to determine latitude and longitude, and before returning to England he laid claim to the land in the name of King George III and his successors. It was thus that a voyage of scientific discovery, organised by one of Europe's prestigious learned scientific society, the Royal Society of London for the purpose of determining the distance of the Earth to the Sun, first brought the British into contact with the eastern coast of Australia and its original inhabitants. Cook proclaimed the land "Terra Nullis" (latin for a 'land belonging to no one', a concept in European international law in the age of European colonisation) against his instructions to negotiate with the original inhabitants. This was the beginning of disadvantage for the original people of Australia. This disadvantage has resonated throughout Australian social, educational and political culture right up to the 21st century. It still remains an important in Australian social and political culture. Successive Prime Ministers and 
Australian governments up to 2008 never had the decency to say sorry to the original inhabitants. It took extraordinary courage and human decency on 13 February 2008 for the present Prime Minister of Australia, Kevin Rudd, to say sorry to the Aboriginal people of Australia for the mistreatment and misdeeds inflicted on them by previous Australian governments and parliaments. Parliaments which begin their day with a prayer to the Lord.

In 2005 the Australian Bureau of Statistics noted that only $29 \%$ of Indigenous students completed Year 12 or the Higher School Certificate (the equivalent of Form 6 in the UK) compared to $65 \%$ for the broader Australian community. Out of the 9000 university science graduates in 2005 only 25 were of Indigenous origin. This is $0.003 \%$ of the number of science students graduating with science degrees. This on all accounts is a national disgrace and a disaster for science education policy for Aboriginal people in Australia. It also highlights the fact that science education policy for Aboriginal people is run by bureaucrats from the humanities with very little knowledge or sympathy for science and engineering.

\section{Background to project}

The University of Western Sydney is located in an area with a large Aboriginal community and a high number of school going Aboriginal students. The number of Aboriginal students studying science and in particular physics at the Higher School Certificate level is minimal. According to the teachers in the Western Suburbs of Sydney, $70 \%$ of Aboriginal students drop out of school before Year 10 (the equivalent of Form 5 in the UK). It is also remarkable that no Aboriginal student has passed though the first year engineering course at the University of Western Sydney in the last 10 years despite the fact that there is a large cohort of Aboriginal students in the schools located around the University of Western Sydney. There is a felt need by the Aboriginal community that Aboriginal students be encouraged to study science and engineering and to consider taking up careers in engineering and science.

With this in mind the author developed a series of astronomy activities in the hope of motivating Aboriginal students to take an interest in science. The project was conducted in the second semester (August to December 2007) of the University term with a group of 15 lower secondary school Aboriginal students. Six projects were undertaken. The facilities of the University Observatory and the physics laboratory in the School of Engineering were utilised for the project. Students not only carried out the projects at the University but also had homework that they did in school as a follow up of what was done at the University.

\section{Aims of the project}

The aims of the project were: to improve the scientific literacy of the students by involving them in a series of astronomy activities which not only used the knowledge of Aboriginal astronomy but also of modern scientific astronomy, to heighten their curiosity about things scientific by looking at the night sky not only with the naked eye but also through the University's fully computerised telescopes, to show how scientists go about the process of exploring natural phenomena and how they test their ideas and models through experiments and observations and to show how two knowledge systems (modern scientific astronomy and Aboriginal astronomy) view the night sky. 


\section{Key performance indicators}

Three key performance indicators were used to assess the success or otherwise of the project. These were: knowledge gained by the students of modern scientific astronomy, knowledge gained by the students of Aboriginal astronomy, knowledge gained by students of the methods and processes of science and change in attitude to further schooling.

\section{Appropriate teaching methods}

There is much debate in the educational literature about learning styles and culture (Claxton \& Murrell 1987; Guild 1994). However, it is difficult to draw any generalisations from these studies because of the complexity and limitations of learning styles as a diagnostic tool. Most of the research in this area is based on studies of the experiences and needs of children from minority cultures in the US with very little work which is relevant to the teaching of Aboriginal students let alone in science and engineering. A hands-on approach was considered the most appropriate method of teaching. This is very similar to the method used for non-Aboriginal students studying science and astronomy. It is the experimental method that is ingrained in the scientific endeavour right from the time of Galileo. The hands-on approach uses concrete experiences and manipulation of scientific apparatus in the laboratory. However, in addition to this we have as suggested by Craven (1999) adopted the method of using a cross-cultural knowledge theme to build on the cultural knowledge base of the students. To this end two knowledge systems and perspectives, i.e. the view of astronomy from an Aboriginal perspective (Bhathal 2006) and the view from modern scientific astronomy (Freedman \& Kauffmann 2007) were used.

Astronomy is one of the oldest of the scientific disciplines and the night sky has intrigued and continues to intrigue human beings. Thus, astronomy provides an excellent vehicle to not only satisfy the natural curiosity of young people about the heavens but also of a way of improving their scientific literacy. By improving their scientific literacy students will be able to explore the natural world on their own and also learn to inquire about the opportunities offered by universities and other educational institutions in terms of preparing themselves for careers in science and engineering.

The project also envisaged that the students would learn the following skills. These included mathematical, scientific (ideas and testing of these ideas), measuring, using and manipulating scientific equipment, drawing inferences, observing the night sky with the naked eye and through telescopes, calculating, drawing graphs and using the graphs to draw conclusions from the data, using art to express ideas, communicating their ideas orally, appreciating two different astronomical knowledge systems, working in groups and learning to use the internet to get information for their projects and other educational interests.

\section{The astronomy projects}

The following six projects were undertaken by the students, viz: the universe, the solar system, properties of light and building a simple telescope, making some astronomical measurements, craters on the Moon and search for life in the universe. An Aboriginal view of some of the astronomical concepts was also incorporated in the projects. Where possible the Aboriginal concepts were illustrated with paintings done by Aboriginal artists.

In each of the projects they learnt a number of skills which we mentioned above. A brief description of what was done in the projects is discussed below. 
The first session began with the origin of the universe. Rather than beginning this session with just the modern scientific conception of the universe it was decided to give the students perspectives from two knowledge systems, viz: the Aboriginal perspective and the perspective from modern scientific astronomy. In the Aboriginal system the universe came into being during the Dreamtime or Alcheringa of the Arunta or Aranda people of central Australia. The Dreamtime is not only an ancient era of creation but continues even today in the spiritual lives of the Aboriginal people. All life - human, animal, bird or fish - is part of an ever-transforming system that can be traced back to the Spirit Anscestors who go about the Earth in an eternal time called the Dreaming. As these spirit people roamed the Earth they made the mountains, rivers, the sky with its celestial objects and all the other features we see in the natural environment around us. The Aborigines are in fact co-creators of the universe they live in. The observer and the observed are the same entity. The Aboriginal view of the universe is illustrated by Aboriginal paintings.

The modern scientific view is then discussed and the students are informed how the universe began with the Big Bang and why scientists think believe it is accelerating. A discussion is then held as to the evidence provided by the astronomers for saying that the universe began with a Big Bang. For their practical the students use a balloon marked with dots to represent the galaxies. They then blow up the balloon and observe and write down how the galaxies are moving away from each other in a similar fashion as astronomers see the galaxies moving away in space. They also do a simple experiment with a spectrometer. They view the spectral lines of hydrogen through a spectrometer and write down the colours of the lines they see in the spectrometer. This experiment illustrates for them what physicists and astronomers mean when they talk about spectral lines. They also use the spectrometer to find out what spectral lines are present in an ordinary lamp by comparing them with the colours in a sodium lamp. This is a simple example of spectral analysis.

For the project on the solar system, the students were provided information on the various aspects of the solar system, i.e. the origin and properties of the solar system. For their experimental work they constructed a solar system mobile based on the properties of the planets in the solar system. By using a weighing machine and measuring their weight on Earth they then calculated their weight on the other planets. This confirmed what they had learnt about the properties of the different planets. The experimentation was followed by viewing the planets through telescopes. This was followed by talking and discussing how the Aboriginal people view the planets and the stories associated with the planets from an Aboriginal perspective. For example, Venus is known as the Morning Star or Barnumbir in Arnhem Land and is associated with death. A discussion of the Morning Star ceremony was also used to highlight the connection between the planets or celestial bodies and their role in the social culture of the Aboriginal people.

In the project on the properties of light the students learnt how the scientific model that light travels in straight lines is tested in the laboratory and how scientists draw inferences from this model of the Rectilinear Propagation of Light (Toulmin 1967). They performed a simple classic experiment (light travels in straight lines) to see how scientists validate their models, scientific theories and ideas with experimentation. They experimented with light beams traveling through various lenses and being reflected from various mirrors. The students were shown how the model that light travels in straight lines is used to explain the length of shadows and how it is also used for practical purposes in making a telescope. The students built a simple telescope with two lenses very much like the telescope that Galileo used in the 16th century to overthrow Aristotelian physics and usher in the scientific revolution (Freedman \& Kauffmann 2007). 
As part of observing the night sky with the naked eye and the telescopes the students were shown how to locate the Southern Cross and how to find their way at night by using the Southern Cross. They were informed that the Southern Cross was first observed by Andreas Corsali, a Florentine traveler who sailed with a Portugeuse expedition to Goa in India in 1515. He described the constellation of stars as a cross or Crux (Bhathal \& Bhathal 2007). He saw the Cross from the perspective of his Christian heritage. But according to Kath Walker (Aboriginal name - Oodgeroo Noonuccal) (1972), a well known Aboriginal poet and writer, long before the Europeans named this group of stars the Southern Cross the Aboriginal people had already called it Mirrabooka. In Arnhem Land the Southern Cross is seen as a shark chasing a sting ray.

The parents were also invited to attend and participate in the astronomy night. This was an important exercise as the parents were able to see first hand what their children were learning and provide the necessary motivation to encourage their children to continue their education to the Higher School Certificate level.

The students were then asked to envisage themselves as living about 10,000 years ago. They were asked to draw the constellation and write and tell the story about the Cross they had written about. Apart from the scientific skill of observing nature, this exercise also developed in them artistic and communication skills.

Project four involved them in making scientific measurements and learning how to use the telescope and the planisphere to find the location of stars. As an exercise in the physics laboratory they found how to measure the distance to a star. They followed the same method that astronomers use in finding the distance to stars but with rather simple laboratory equipment. The aim of this project was to show the process of science.

The fifth project dealt with craters on the Moon and how they were formed. A discussion on asteroids and their impact on life on Earth generated a lot of interest. The students did an experiment in the laboratory with a sand tray to represent the surface of the Moon. They dropped various sized steel balls from different heights and measured the diameters of the craters that were formed. They then drew graphs and extracted information and made inferences from the graphs. This part of the project concluded by talking and discussing how the Moon was formed from a modern scientific point of view and how the Aboriginal people thought the Moon was formed and how they explained the phases of the Moon. We also discussed Aboriginal stories about the Moon in the context of their social culture.

The final project discussed the search for life in the universe. The search and origin of life in the universe is a NASA flagship program. We used this project to inform the students what is happening at the forefront of astronomy research in the area of finding life elsewhere in the universe. They were asked to design a message to ET. In designing their message they were asked to take into consideration some of the following questions: Should the message be mathematical? Should it be a drawing? Should it have chemical symbols? Should it be in binary numbers? etc. After having completed their designs the students were asked to tell the class about their design and defend it.

\section{Outcomes}

One of the surprising outcomes of the project was that the students had very little prior knowledge of Aboriginal astronomy. This is partly due to the fact that successive Australian governments had over the years attempted to "wash out" the Aboriginality and Aboriginal culture from earlier generations of Aboriginal people (Human Rights and Equal Opportunity Commission 1993). At the end of the project the students said that they knew more about Aboriginal astronomy now than when they first started the 
project. All of them not only found astronomy interesting but they loved looking at the heavens through the telescopes. This is similar to what is found in the general population who visit the University's Observatory on astronomy nights for the public. They found that the experiments they conducted at the University interesting and said that they would like similar experiments to be done at school. Most of the students found school science boring. Only 7 per cent of the students agreed with the statement "Science is about ideas and experiments to test whether they are right or wrong" at the start of the project. At the end of the project 93 per cent agreed with the statement. It was also interesting to find out that more students (67 per cent) were considering carrying on to do the Higher School Certificate after participating in the project than before they participated in the project (20 per cent).

The overall outcome of the project was positive in changing their attitudes to science and its processes. They gained knowledge of Aboriginal astronomy and modern scientific astronomy and were able to appreciate that there were two world views of the universe, viz: a socio-cultural and a scientific. A greater percentage of the students would like to continue their studies up to the Higher School Certificate level after participating in the project.

Part of the project was shown on national TV news as an item of significance in Aboriginal science education in Australia.

\section{References}

Badger, G. M. (ed) 1970, Captain Cook: navigator and scientist (Canberra: Australian National University Press)

Bhathal, R. \& Bhathal, J. 2007, Australian backyard astronomy, 2nd edition (Canberra: National Library of Australia)

Bhathal, R. 2006, Astronomy \& Geophysics, 4727

Claxton, C. S. \& Murrell, P. H. 1987, Learning styles: implications for improving educational practices (Washington: Clearinghouse on Higher Education)

Craven, R. (ed). 1999, Teaching Aboriginal studies (Crows Nest: Allen \& Unwin)

Freedman, R. A. \& Kaufmann III, W. J. 2007, Universe (New York: W. H. Freeman \& Company)

Guild, P. 1994, Educational Leadership, 51, 16

Human Rights and Equal Opportunity Commission 1997, Bringing them home : National inquiry into the separation of Aboriginal and Torres Strait Islander children from their families (Sydney: HREOC)

Toulmin, S. 1967, The philosophy of science (London: Hutchinson University Library)

Walker, K. 1972, Stradbroke Dreamtime (Sydney: Angus \& Robertson) 